\title{
Case-technologies in practice-oriented training of future teachers of preschool and primary general education
}

\author{
N.A. Gushchina ${ }^{1 *}$, V.N. Zinovieva ${ }^{2}$, and I.V. Mikityuk ${ }^{3}$ \\ ${ }^{1}$ K.E. Tsiolkoskiy Kaluga State University, Kaluga, Russia \\ ${ }^{2}$ K.E. Tsiolkoskiy Kaluga State University, Kaluga, Russia \\ ${ }^{3}$ K.E.Tsiolkoskiy Kaluga State University, Kaluga, Russia
}

\begin{abstract}
The article deals with the problem of convergence of fundamental pedagogical education in higher education and real pedagogical practice in preschool organizations and primary schools for the formation of children's cognitive activity. The article presents the experience of testing pedagogical conditions for the use of case technologies in preparing future teachers for the process of forming prerequisites for cognitive activity in preschool age and cognitive universal educational actions in primary school age.
\end{abstract}

\section{A problem statement}

Transformations in modern pedagogy have led to major changes in the system of preschool and primary education. They especially touched upon the organizational and content aspects of the level of education.

Today in the university it still remains nun resolved question of the development of the means of professional competence, which is associated with the ability to use modern training technologies. One of the most interesting new and specific technologies is a case technology. Recently solving cases technology became widely used in education, considered as one of the most effective training techniques. In this regard, we think that this technology is an opportunity for the formation of professional competence, and also is an opportunity to enrich ideas of future teachers about case technology not only in theory, but also in practice. The content of the case technology is productively built on the basis of problem situations based on the actual needs of preschool and school organizations in accordance with the pedagogical disciplines and curriculum. We consider as very actual and useful the idea of continuity of preschool and primary education both in the field of education and in the worldview in general.

Therefore, the problem of adaptation to the case method of professional training in high school in order to study the features of continuity in preschool pedagogy is, with the formation of the professional competence, coupled with the ability to use today is very important. We see its solution in the development of a special type of cognitive cases,

*Corresponding author: prof-ped.gpa@mail.ru 
including the requirements of both the Federal State Educational Standard of Preschool Education and the Federal State Educational Standard of Primary General Education, and the requirements of the Professional Standard of a Teacher.

The idea of our research is to identify the conditions for the formation of continuity from the perspective of the formation of ideas about universal cognitive educational actions in students of the direction "Pedagogical education" of the profiles "Pedagogy and methodology of primary education" and "Pedagogy and methodology of preschool education" using case technology.

\subsection{The objective of the work}

And the analysis of the latest achievements and publications in which the solution of this problem has been started, the identification of previously unresolved parts of the general problem to which this article is devoted, determines the focus on taking into account organizational and pedagogical conditions that contribute to the formation of neoplasms of the child that are significant for further development, education and training. preschool age [1,2], and later the primary school pupil through the integrative approach and the diversity of the educational process found confirmation in both russian studies $x[3,4,5]$ so and abroad $[6,7,8]$.

In recent years many authors prove that systematic monitoring of various areas of continuity of preschool and primary education, various principles and approaches in its study allowed to show it as a teacher's training process to ensure regular connection between the stages of adolescent development, including organizational, pedagogical, psychological conditions aimed at the integral and progressive development and selfdevelopment of the individual in the transitional periods from preschool childhood to school [3, 9].

The old paradigm is not able to meet these requirements fully, since it is more focused on the transfer and assimilation of knowledge, and not on the methods of activity. The case method refers to the methods of active, problematic, situational analysis and has wide application in the practice of teaching pedagogical disciplines.

The essence of this educational technology lies in the fact that the assimilation of the material is "the result of high students' self-activity in resolving contradictions, as a result of which there is a creative mastery of professional knowledge and skills and the development of thinking abilities" $[10,11]$.

In most cases, the situation of the proposed cases is a combination of different states.

Within the framework of different approaches, case technologies are implemented in different ways. It is known that at Harvard School, teaching with the use of case technologies is considered as a form of rather intensive training, which is allocated up to $90 \%$ of educational time and which is devoted to discipline. In order for students to feel like participants in real events, an indispensable condition is that they should rely on data from real life.

The European approach to the analysis of cases coincides with the previous one in that the situation presented in the case should be borrowed from the activities of existing companies. However, its description is shorter, and the decision taken during the joint discussion is more open and obvious.

In contrast to the above approaches, the Chicago case technology provides a comprehensive, detailed analysis of a social phenomenon, information about which is obtained empirically. The focus of the case study method on research activities led to the fact that education began to be viewed from a pragmatic standpoint. According to J. Dewey, education is a condition for improving adaptation to life, during which the student is engaged in what meets his interests and needs. Thus, the 
case study method becomes a means of adaptation to the surrounding social, industrial reality.

Russian scientists considered the ideas of D. Dewey's pragmatic philosophy reasonable and began to use the project method that recreates real life situations [12]. These methods made it possible to use the experience of students to improve the quality of education and were very close in their essence to the method of cases.

Analyzing the research of scientists, we can conclude that the case method, based on the provisions of different approaches, is an integrative method [9]. First of all, a case is anaccidentor description of a practical situation that took place in a specific, reallife institution.

In addition to the above skills, the case method forms the ability to find and apply the most effective techniques to achieve the maximum result depending on the situation, to find quickly alternative solutions and to be responsible for them in conditions of high uncertainty $[1,13]$ of the educational environment.

In addition to the fact that the case contains information about the events, the people involved in them, the time frame, the available resources and powers necessary to achieve the tasks, modeling the result itself, it programs the students to identify and search for the author's solution to the problem. Thus, the inclusion of problem learning in the method of cases is observed $[2,10,11,14,15]$. The problematic task presented in the case contributes to the development of critical, analytical thinking, predictive skills. Problematic presentation and organization of the material, assumed by the case, ensures the introduction of an element of novelty into the educational process. Immersing through a case study in modern realities, students get the opportunity to apply their knowledge in practice, acquire new dynamic and professional knowledge through interaction and exchange of experience with other students. The case helps students to discover new ways for self-improvement, to develop their personal and professional qualities, and it leads to amotivation increase and, as a result, students' creative independence.

Based on the analysis, the following definition of the case method was formulated. The case method is an active, problem-based teaching method that uses description and system analysis of real events (situations) from the life of organizations, aimed at successful socialization of the individual, improving professional skills through the creation and immersion of students in the context of educational processes.

\section{Results of the research}

The purpose of the study was theoretical substantiation, design and experimental approbation of educational cases as a means of practice-oriented training of teachers of vocational education at a university to implement the continuity of preschool and primary general education in the context of lifelong education on the example of the formation of prerequisites for cognitive universal educational actions in childhood.

Work tasks:

1. Based on the analysis of scientific and scientific-methodical literature, to clarify the essence and structure of the concept of cognitive universal educational actions and to develop the basis for its formation among students of the next directions: "Pedagogy and methodology of primary education" and "Pedagogy and methodology of preschool education", including methodological approaches, stages and criteria for the formation of its components.

2. To develop and scientifically substantiate the formation of the model of cognitive universal educational actions among students of successive profiles based on the use of case technology. 
3. To identify the pedagogical conditions that increase the effectiveness of skill formation among students of the Institute of Pedagogy.

In a study conducted on the basis of the Institute of Pedagogy of KSU named after K.E. Tsiolkovsky, 3 teachers and 64 students aged 18-25 of part - full-time and parttime students from the faculty of "Pedagogical education", profiles "Pedagogy and methods of primary education" and "Pedagogy and methods of preschool education." This technology arouses of great interest, both among full-time students who do not have work experience, and part-time students, many of whom are already working in educational institutions.

According to A.V. Zaporozhets, it should allocate the two ways in which you can direct the mental development of children of preschool age, one of which involves the acceleration of development, when the child as quickly as possible is "dragged" from one stage to another, inhibiting activities and psychological quality, which are inherent to the previous stage, which may slow down the speed of the child's progress. According to another way, it is advisable to expand, enrich the developmental aspects characteristic of each age stage and to cultivate new psychological qualities not in spite of them, but on their basis.

When applied to teaching six-year-olds, the first path meant an attempt to "immerse" them immediately in traditional forms of school life, "to low" down the content and teaching methods characteristic of seven-year-old children, by simplifying them partly, and that led to the fact that a significant part of children would not be able to enter school life in a timely manner and fell into the category of unsuccessful. At the same time, a sharp change in the requirements for behavior and the need for systematic fulfillment of educational tasks led to a negative attitude towards school, negative self-esteem, etc. In addition, even if the students were able to switch to a new lifestyle and activity in time, this would lead to the cessation of the further development of important psychological qualities that develop in preschool childhood.

In this aspect, this study complements the previous scientific developments with the proposed system of a holistic educational process based on continuity in the professional students training at a pedagogical university. The implementation of which, ultimately, as the statistically significant results of the study show, stimulates respondents to increase their professional activity and to increase the level of their competence.

The organization of work with the case included several stages: 1 . The preparatory stage, where the teacher created the optimal selection of material for the case, developed options for solving problem situations, prepared students for a new form of work. 2 . The stage of immersion in joint activities, where the formation of motivation for joint activities, the manifestation of the participants' initiatives. At this stage, the text of the case was distributed to the students, the main tasksof the case were identified. 3. The stage of organizing joint activities to solve the problem, where students were distributed into groups and answered questions in the allotted time, a speaker was selected who was going to present the solution. 4. The stage of the analysis of joint activities, where the educational and training results of working with the case are manifested.

Analyzing the case, students were asked to highlight the main idea and to use the following words to connect thought and argument: therefore, it is not surprising that ..., this is why ..., from here follows ..., now it becomes clear ..., now there is an opportunity ..., precisely because of this ..., this leads to the fact that ...; justification of arguments, formulation of the conclusion.

Discipline: Preschool Pedagogy

Case type: Training case

Case type: Analytical 
The specified educational case is used in the implementation of the content of the educational subject "Preschool Pedagogy".

In particular, the presented educational case allows us to determine the level of formation of successive ties among students about the prerequisites of cultural skills in preschool age and universal educational actions in primary school, namely:

- cognitive universal learning activities: formation of the ability to perceive information from memory, work with various sources of information, work with text, pictures, diagrams.

Educational case number 1 "Cognitive universal educational actions".

Group assignment:

1. Make a mind map on the topic.

2. Select two illustrations for comparative analysis (for comparison and finding differences).

3. Determine the types of tasks for the formation of cognitive universal learning activities.

Educational case number 2. "Options for monitoring the cognitive activity of children".

1. Prepare questions for monitoring the cognitive activity of children in free children's activities (in accordance with Federal State Educational Standard for Preschool Education).

2. Analyze the content of the questions to divide into groups.

3. Select diagnostic techniques for determining cause-and-effect relationships.

Educational case No. 3. Topic "Observation of the nature of manifestations of cognitive interest and cognitive activity of activity in the course of educational activities".

1. Determine the indicators of manifestations of the severity of cognitive interest.

2. Describe the criteria for assessing the indicators of manifestations.

3. Assess all three components of cognitive interest.

Learned skills:

Analytical: the ability to analyze data in the educational area "Cognitive development" and cognitive universal educational actions, to highlight essential and non-essential information.

Practical: the use of theoretical knowledge, patterns, principles and methods in practice.

Creative: developing lateral thinking and a critical approach to problem solving.

Communicative: the ability to convincingly lead a discussion, defend one's own point of view.

Social: the ability to listen, to argue opinions, to control oneself.

Self-analysis: being aware and analyzing the opinions of others and one's own.

\section{Conclusions}

We propose this case technology as a basic pedagogical toolkit, within the framework of which there is a solution of pedagogical problematic situations are differentiated by the degree of complexity and professional significance that arise in the professional sphere.

The obtained research data showed that it is advisable for the profiles "Pedagogy and methodology of primary education" and "Pedagogy and methodology of preschool education" to coordinate on the basis of state educational standards of higher pedagogical education and the requirements of the Federal State Educational Standard for Preschool Education and the Federal State Educational Standard for Primary General Education while drawing up the associated curricula. The special relevance and novelty of the developed material for ensuring continuity is due to the fact that the curricula of the Institute of Pedagogy the basic methods of preschool and primary general education are retained, for example: "Methodology for the development of preschool children" (3.4 semester) is 
followed by the "Methodology for teaching the Russian language in primary school" (4.5 semester).

It is planned to expand interdisciplinary connections, to develop integrated modules at each stage of the educational process in order to form a holistic view of the content and types of professional (pedagogical) activities in students, to determine reporting forms for each discipline within the module and the module as a whole while creating an associated educational program. At the same time, analytical work to differentiate the content and requirements for the level of training in disciplines of different profiles is carried out.

Thus, we come to the conclusion that, in general, the implementation of training in the two-profile bachelor's degree "Pedagogy and Methods of Primary Education" and "Pedagogy and Methods of Preschool Education" forms the necessary professional competencies in students at basic and advanced levels.

Nevertheless, the implementation of our development contributes to the formation of readiness to use the capabilities of the educational environment to achieve metasubject learning outcomes and ensure the quality of the educational process by means of the subjects taught. It should also be noted that there is a comparative positive dynamics in the academic performance of students in the field practice "The first days of a child in school", especially in the profile "Pedagogy and methods of preschool education." It is noteworthy that the students of this group have repeatedly received letters of thanks from the heads of educational organizations of the combined type "kindergarten-school" for the fact that they were able to apply modern methods and technologies of teaching in the aspect of systemic design of psychological and pedagogical conditions for ensuring continuity in work with children.

In general, the results of this study are consistent with the results of other studies on the implementation of professional training of students - future educators and teachers in the aspect of continuity of preschool and primary education in modern conditions.

\section{References}

1. M.V. Antonova, Psychological and Educational Support in Professional SelfDetermination in Students: Through the Lens of Professional Standard for Teachers, 8, 2, 29-39 (2016)

2. A.M. Dolgorukov, The case-study method as a modern technology of professionallyoriented training - $\quad$ [Electronic resource] http://www.vshu.ru/lections.php?tab_id=3\&a=info\&id=2600 (accessed: 20.09.2020)

3. M.V. Volkova, N.A. Gushchina, Features of formation of cognitive universal educational actions in children at preschool age and primary school // In the collection: Scientific works of Kaluga state University named after K.E. Tsiolkovsky. Materials of reports of psychological and pedagogical sections of the regional University scientific and practical conference. Ser. "Psychological and pedagogical Sciences", 116-122 (2017)

4. O.V. Dubovik, Features of the professional training system in the USA, 10 (13), 81-85 (2014)

5. M.V. Korepanova, G.V. Gnaykova, Continuity in the social and personal development of children during the transition from preschool to primary school age: the main results of the Federal experiment, Elementary school plus Before and after, 5, 57-60 (2014) 
6. R.S. Nagovitsyn, O.E. Danilov, A.V. Tutolmin, D.Yu. Scriabina, Continuity in continuous training of teachers for preschool and primary General education, Prospects For science and education, 4 (40), 194-203 (2019)

7. G.P. Novikova, Formation of teacher's readiness to ensure continuity of preschool and primary school education. Pedagogical education and science, 6, 4-10 (2009)

8. On approval of the Federal state educational standard of higher education bachelor's degree in the field of training 44.03.01 Pedagogical education: order No. 121 of February 22, [Electronic resource]. - URL: https:// Ministry of education and science. RF/documents/12496 (date accessed: 21.09.2020) (2018)

9. The concept of the content of continuous education (preschool and primary link), Primary school, 4, 3-20 (2000)

10. I.E. Kulikovskaya, Terminology of modern preschool educat on, 200 (2014)

11. O.A. Lyubchenko, A.S. Lvova, Modular construction of practice-oriented teacher training, Humanities and social Sciences, 4, 127-134 (2015)

12. A.K. Nyssa, Problem of transition to school. Review of international practices of training children, organization of continuity of educational content, interaction of parents and educational organizations, Modern preschool education, 1(91), 18-33 (2019)

13. N.N. Murovanaya, Model of practice-oriented training of future teachers in the field of preschool and primary General education: conceptual and technological foundations, Humanities, 1, 60-64 (2020)

14. N. Pavelieva, The case method in professional education. - [Electronic resource] http://www.znanie.org/jornal/n3_08/Pavel3.pdf (date accessed: 20.09.2020)

15. Teacher (pedagogical activity in the field of preschool, primary General, basic General, secondary General education) (educator, teacher): professional standard. Approved by the order of the Ministry of labor of the Russian Federation of 5 Avgusta 2016. 422n. URL: http://www.pravo.gov.ru/ (accessed 10.09.2020) 